\title{
Post-marketing assessment of content and efficacy of preservatives in artemisinin-derived antimalarial dry suspensions for paediatric
}

\section{use}

\author{
Magnus A Atemnkeng, Katelijne De Cock and Jacqueline Plaizier- \\ Vercammen*
}

\author{
Address: Department of Pharmaceutical Technology and Physical Pharmacy, Faculty of Medicine and Pharmacy, Vrije Universiteit Brussel, \\ Laarbeeklaan 103, B-1090 Brussels. Belgium \\ Email: Magnus A Atemnkeng - matemnke@vub.ac.be; Katelijne De Cock - kdecock@vub.ac.be; Jacqueline Plaizier- \\ Vercammen* - jplaizie@vub.ac.be \\ * Corresponding author
}

Published: 26 January 2007

Malaria Journal 2007, 6:12 doi:10.1186/1475-2875-6-12
Received: 17 October 2006

Accepted: 26 January 2007

This article is available from: http://www.malariajournal.com/content/6/l//2

C 2007 Atemnkeng et al; licensee BioMed Central Ltd.

This is an Open Access article distributed under the terms of the Creative Commons Attribution License (http://creativecommons.org/licenses/by/2.0), which permits unrestricted use, distribution, and reproduction in any medium, provided the original work is properly cited.

\begin{abstract}
Background: Artemisinin-derivative formulations are now widely used to treat falciparum malaria. However, the dry powder suspensions developed for children are few and/or are of poor quality. In addition to the active compound, the presence of a suitable preservative in these medicines is essential. In this study, an evaluation of the preservative content and efficacy in some dry suspensions available on the Kenyan market was performed.
\end{abstract}

Method: UV spectrophotometry was used to identify the preservatives in each sample while HPLC-UV was used for quantification. After reconstitution of the powders in water, the dissolution of the preservatives was followed for 7 days. Antimicrobial efficacy of the preservatives was assessed by conducting a preservative efficacy test (PET) following the European pharmacopoeia standards.

Results: Four different preservatives were identified namely methylparahydroxybenzoate (MP), propylparahydroxybenzoate (PP), benzoic acid and sorbic acid. MP and PP were identified in Artesiane ${ }^{\circledR}$ (artemether $300 \mathrm{mg} / 100 \mathrm{ml}$ ), Alaxin ${ }^{\circledR}$ (dihydroartemisinin $160 \mathrm{mg} / 80 \mathrm{ml}$ ) andGvither ${ }^{\circledR}$ (artemether $300 \mathrm{mg} / 100 \mathrm{ml}$ ) respectively. Sorbic acid was presentin Artenam ${ }^{\circledR}$ (artemether 180 $\mathrm{mg} / 60 \mathrm{ml}$ ) while benzoic acid was identified in Santecxin ${ }^{\circledR}$ (dihydroartemisinin $160 \mathrm{mg} / 80 \mathrm{ml}$ ) andArtexin ${ }^{\circledR}$ (dihydroartemisinin $160 \mathrm{mg} / 80 \mathrm{ml}$ ) respectively. Cotecxin ${ }^{\circledR}$ (dihydroartemisinin 160 $\mathrm{mg} / 80 \mathrm{ml}$ ) did not contain any of the above preservatives. After reconstitution in water, preservativesin $50 \%(3 / 6)$ of the products did not completely dissolve and the PET results revealed that only Artenam ${ }^{\circledR}$ and Gvither $^{\circledR}$ met the requirements for antimicrobial efficacy. The other products did not conform.

Conclusion: These results show that paediatric antimalarial dry powder formulations on the market may contain ineffective or incorrect amounts of preservatives. This is a potential risk to the patient. Studies conducted on the dry powder suspensions should include the analysis of both the active ingredient and the preservative, including the efficacy of the latter. 


\section{Background}

The artemisinin-derivatives, artemether, artesunate, arteether and dihydroartemisinin, are currently the most potent antimalarial medicines on the market. They are widely available in the different pharmaceutical dosage forms including tablets, injections, suppositories and dry powders [1].

Since artemisinin and its derivatives are poorly water-soluble and are not very stable in solution, the preparations have to be formulated in the dry form for subsequent reconstitution into a wet suspension with water just before use. The dry powders for reconstitution are normally designed for children from $0-5$ years of age, who are not able to swallow tablets. In the malaria endemic countries, living conditions are often poor, including scarce access to clean portable drinking water [2]. As a result, microorganisms can easily thrive when the dry powder is reconstituted with poor quality water. In addition, children suffering from malaria, as well as AIDS or typhoid, have a weakened immunological system and are, therefore, more susceptible to other infections. Moreover, the drugs are packaged in multiple dose containers, making the preparation highly susceptible to contamination following frequent use. Hence, pharmaceutical preparations which need an aqueous vehicle such as syrups and powders for oral suspensions require safeguards from microbial contamination, which may affect product stability or infect the consumer. This is accomplished by the addition of antimicrobial agents in the formulation to destroy and inhibit the growth of those organisms that may contaminate the product during manufacture or use [3].

The International Committee on Harmonization (ICH) guidelines [4] requests that for submission of drug registration dossier on dry powders for oral suspensions, data should be provided for the content of the active pharmaceutical ingredient (API) as well as the type(s) and amount(s) of the preservative(s) used. In addition, the efficacy of the antimicrobial preservation should be demonstrated by challenging the reconstituted suspension in its final container with specified microorganisms. This implies that the preservative used in the dry powder must completely dissolve on addition of water to impart the preservation action.

Sources of this microbial contamination may include air and water, manufacturing equipment, manufacturing personnel and/or the consumer [5]. Bacterial contamination of products through consumer use, has resulted in presence of mixed and harmful microbial flora in the product [6].
Major studies on antimalarial formulations are limited to the active ingredients without mention of the preservatives when studied in syrups and dry powders. In view of the biological role that this excipient plays towards the maintenance of the preparation and the recovery of the patient, there is a dire need for greater attention and awareness directed towards the importance of preservation in paediatric formulations.

Several chemical preservative agents exist and have been widely employed in the cosmetic, food and pharmaceutical industries [5]. For oral use, the choices of the preservatives are limited. These include benzoic acid (BA) $\mathrm{C}_{6} \mathrm{H}_{5} \mathrm{COOH}$ and sorbic acid (SA) $\mathrm{C}_{5} \mathrm{H}_{7} \mathrm{COOH}$, which are generally effective to control mould and yeast growth, and the parahydroxybenzoic acid esters: methylparaben (MP) $\mathrm{C}_{6} \mathrm{H}_{4}(\mathrm{OH}) \mathrm{COOCH}_{3}$ and propylparaben (PP) $\mathrm{C}_{6} \mathrm{H}_{4}(\mathrm{OH}) \mathrm{COOC}_{3} \mathrm{H}_{7}$, which are most commonly used to control bacterial growth due to their broad antimicrobial spectrum with good stability and non-volatility [7]. MP and PP are usually used in combination as they possess a synergistic activity when used together. However, overuse of preservatives may cause allergic reactions hence, they should be shown not to be cytotoxic or sensitizing $[8,9]$.

Recently, the artemisinin-derivative drugs have become a major target for counterfeiters. Fake and substandard versions of original brands have previously been reported in Southeast Asia [10,11] and now in Africa [12]. The substandard copies were present in all dosage forms but most especially in the tablets and dry powders. In the latter, quality analysis should also be performed on the preservatives. No report has been published on efficacy of preservatives in artemisinin-like antimalarial drugs.

Thus, the aim of this study was (1) to identify the commonly used antimicrobial agents in the artemisinin-containing dry suspensions on the market, (2) study the dissolution profiles of these preservatives after reconstituting in water, (3) evaluate the activity of the preservatives by performing the preservative efficacy test (PET) on the wet suspension and (4) describe some simple analytical procedures for these analytes in dry powders. The different high performance liquid chromatography (HPLC) methods used were validated for each analyte.

\section{Methods}

\section{Materials and reagents}

Potassium dihydrogenphosphate and sodium hydroxide (both Ph. Eur. grade) were obtained from Merck (Darmstadt, Germany) and HPLC grade methanol and acetonitrile were supplied by Fisher Scientific (Leicestershire, UK). Glacial acetic acid was obtained from JT Baker (Deventer, The Netherlands) while ammonia (pro analysi) was supplied by Merck (Darmstadt, Germany). 
Methylparaben and propylparaben were obtained from Federa (Brussels, Belgium), while benzoic acid (pro analysi) was supplied by Merck (Darmstadt, Germany). Sorbic acid was bought from Certa (Braine l'Alleud, Belgium). De-ionized milli-Q water was used throughout the experiment.

\section{Thin layer chromatography (TLC) for the identification of preservatives}

Of the seven dry suspensions, only the Artenam ${ }^{\circledast}$ and Artesiane $^{\circledast}$ samples indicated the type of preservative(s) used on the package insert. From the literature, the commonly used preservatives in oral aqueous pharmaceuticals were retrieved and used to identify the preservatives in the other samples. The TLC procedure described in the Ph. Eur. IV for the identification of parabens was initially tested to separate the four preservatives.

Ca. $100 \mathrm{mg}$ of each of the reference preservative powder was weighed in separate 100-ml flasks and dissolved to the mark with methanol. The stationary phase was $10 \mathrm{~cm}$ $\times 20 \mathrm{~cm}$ RP-18 $\mathrm{F}_{254 \mathrm{~S}}$ silica gel plates from Merck (Darmstadt, Germany). The initial eluent was composed of 70 volumes of methanol, 30 volumes of water and 1 volume of glacial acetic acid. Several other compositions were tested to efficiently separate the four components on a single plate (see Table 1 ). Five $\mu$ l of each standard solution was manually spotted using a glass capillary pipette at 2 $\mathrm{cm}$ spot distance. The plates were then developed in Camag $^{\circledR}$ TLC tanks presaturated with mobile phase. Development time was dependent on eluent composition, but \pm 30 min was sufficient for most. The plates were allowed to dry in a well ventilated room. Visualization was on UV at $254 \mathrm{~nm}$ with a Camag ${ }^{\circledR}$ Universal UV Lamp (Muttenz, Switzerland).

\section{UV spectrophotometry}

To identify the preservatives in the other suspensions, methanol was added to each powder bottle, mixed and centrifuged at $3,000 \mathrm{rpm}(g=1,512)$ for $15 \mathrm{~min}$. The supernatant was collected and appropriate dilutions were made in methanol. Spectra acquisition of the samples was done against a standard solution on a Uvikon 860 spec- trophotometer (Kontron Instruments, Massachusetts, USA) connected to a Plotter 800 Integrator (Kontron Instruments, Massachussetts, USA). Pure methanol was used as the blank.

\section{HPLC instrumentation}

The chromatographic system for the preservatives (MP, PP, BA and SA) consisted of a Merck-Hitachi L-6000 pump, a Perkin-Elmer LC 90 UV spectrophotometric detector connected to a Merck-Hitachi D-2500 ChromatoIntegrator. The stationary phase in each case was a reversed-phase Nucleosil $^{\otimes} 120-4 \mathrm{C}_{18}$ column, $125 \mathrm{~mm}$ long by $4 \mathrm{~mm}$ (i.d) and $5 \mu \mathrm{m}$ particle size from MachereyNagel (Düren, Germany) except for sorbic acid where a Lichrospher $^{\circledR} 250 \times 4 \mathrm{~mm}, 5 \mu \mathrm{m}$ particle size column from Merck(Darmstadt, Germany)was used. The eluent for the parabens consisted of an acetonitrile : $\mathrm{KH}_{2} \mathrm{PO}_{4}(0.05 \mathrm{M}$, $\mathrm{pH} 5.0)$ buffer (300:700, v/v) mixture. The mobile phase of sorbic acid was composed of a mixture of acetonitrile : water : $\mathrm{KH}_{2} \mathrm{PO}_{4}(0.05 \mathrm{M}, \mathrm{pH} 5.0)$ buffer,(100:690:240, v/v/ $\mathrm{v}$ )and benzoic acid was separated using acetonitrile : $\mathrm{KH}_{2} \mathrm{PO}_{4}(0.05 \mathrm{M}$, pH 5.0) buffer(100:900, v/v) mixture. Detection of MP and PP was achieved on UV at $254 \mathrm{~nm}$, $290 \mathrm{~nm}$ for sorbic acid and $226 \mathrm{~nm}$ for benzoic acid. All analyses were done isocratically at a flow rate of $1.0 \mathrm{ml} /$ min and $20 \mu \mathrm{l}$ of each sample was injected. In all experiments, the buffer was adjusted to there quired $\mathrm{pH}$ with sodium hydroxide and filtered using a $0.45 \mu \mathrm{m}$ pore size membrane filter before use.

\section{Standard solutions preparation}

A bulk powder mixture comprising of ca. $0.08 \% \mathrm{MP}$ and $0.02 \%$ PP was prepared and from this mixture about 50 mg was accurately weighed in a $50-\mathrm{ml}$ flask. This was completely dissolved to the mark with pure methanol. The solution was then diluted (100x) with the same solvent for analysis. Sorbic acid standard solution was prepared by weighing ca. $160 \mathrm{mg}$ of it and dissolving in $50 \mathrm{ml}$ methanol. Appropriate dilutions were then made, first $10 \mathrm{x}$ in methanol : water $(4: 1, \mathrm{v} / \mathrm{v})$ mixture and then $2.5 \mathrm{x}$ with the mobile phase for injection. Benzoic acid standard was prepared by accurately weighing $60 \mathrm{mg}$ of it in a 50$\mathrm{ml}$ volumetric flask and dissolving to the mark with a

Table I: Mobile phase compositions for the separation of preservatives by TLC (detected at $254 \mathrm{~nm}$ )

\begin{tabular}{|c|c|c|c|c|}
\hline \multirow[b]{2}{*}{ Mobile phase $(v / v / v)$} & \multicolumn{4}{|c|}{ Retardation factor $\left(R_{F}\right)$} \\
\hline & Methylparaben & Propylparaben & Sorbic acid & Benzoic acid \\
\hline $\mathrm{CH}_{3} \mathrm{OH} / \mathrm{H}_{2} \mathrm{O}(80 / 20)$ & 0.70 & 0.57 & 0.68 & 0.69 (Faint spot) \\
\hline $\mathrm{CH}_{3} \mathrm{OH} / \mathrm{H}_{2} \mathrm{O} / \mathrm{CH}_{3} \mathrm{COOH}(70 / 30 / \mathrm{I})$ & 0.47 & 0.28 & 0.47 & 0.50 (Faint spot) \\
\hline $\mathrm{CH}_{3} \mathrm{OH} / \mathrm{H}_{2} \mathrm{O} / \mathrm{CH}_{3} \mathrm{COOH}(80 / 20 / \mathrm{I})$ & 0.75 & 0.67 & 0.75 & 0.75 \\
\hline $\mathrm{CH}_{3} \mathrm{OH} / \mathrm{H}_{2} \mathrm{O} / \mathrm{CH}_{3} \mathrm{COOH}(80 / 20 / 3)$ & 0.57 & 0.48 & 0.64 & 0.64 (Faint spot) \\
\hline $\mathrm{CH}_{3} \mathrm{OH} / \mathrm{H}_{2} \mathrm{O} / \mathrm{NH}_{3}(80 / 20 / \mathrm{I})$ & 0.80 & 0.70 & 0.87 & Highly faint spot \\
\hline $\mathrm{CH}_{3} \mathrm{CN} / \mathrm{H}_{2} \mathrm{O} / \mathrm{CH}_{3} \mathrm{COOH}(95 / 5 / \mathrm{I})$ & 0.88 & 0.81 & 0.84 & Highly faint spot \\
\hline
\end{tabular}


methanol : water $(900: 100, v / v)$ mixture. From this a $20 \mathrm{x}$ dilution was made with a methanol : $\mathrm{KH}_{2} \mathrm{PO}_{4}(0.05 \mathrm{M}$, pH 5.0) buffer (50:50 v/v).

\section{Preservative content in dry powders}

All powders analysed in this study were anonymously obtained from pharmacies within Nairobi in Kenya (East Africa). An Artenam ${ }^{\circledast}$ semi-industrial batch dry powder suspension containing artemether $(180 \mathrm{mg} / 60 \mathrm{ml})$ was added to the study. From each product the following were noted: type and dose of active ingredient and type of preservative (if indicated) and registration status. All analyses were performed before the expiry dates of the product.

Powder in each bottle was shaken to free the particles. For the dihydroartemisinin dry powders, exactly $200 \mathrm{ml}$ of methanol : water $(80: 20, \mathrm{v} / \mathrm{v})$ mixture was added to reduce the influence of the matrix and powder volume on the analysis. This solvent mixture was necessary to dissolve both the active and the preservative in order to use the content of the same bottle for both analyses. For the artemether dry powders, exactly $200 \mathrm{ml}$ of pure methanol was added to the content. All the bottles were then thoroughly mixed and left on the shaking apparatus for at least 1 hour followed by ultrasonication for $15 \mathrm{~min}$. Part of the suspension was transferred to 5-ml Falcon ${ }^{\circledR}$ tubes and centrifuged at 3,000 rpm $(g=1,512)$ for $15 \mathrm{~min}$.

\section{Dissolution of preservatives in the reconstituted suspensions}

The instructions described by each manufacturer were followed for reconstitution. Milli-Q water was added to each powder, well mixed till complete dispersion and part of the suspension was taken to determine its $\mathrm{pH}$. From the rest a suitable volume was transferred to Falcon ${ }^{\circledR}$ tubes and centrifuged at 3,000 rpm $(g=1,512)$ for $15 \mathrm{~min}$. For the more viscous suspensions, the centrifugation step was repeated on the supernatant. The density of the supernatant was measured and subsequent volumes were determined by sample weighing. Appropriate dilutions of the supernatant were done for HPLC analysis at the following time points: immediately after reconstitution $\left(t_{0}\right), 6$ hours, 24 hours, 4 days and 7 days respectively; the maximum period necessary for a complete treatment of severe malaria and during which the suspension is supposed to be stable.

\section{Preservative efficacy test}

The method described in the European Pharmacopoeia IV 5.1.3 'Efficacy of Antimicrobial Preservation' was used [3]. The test consisted of challenging the reconstituted suspensions in their final containers with a prescribed inoculum of the following micro-organisms: Pseudomonas aeruginosa ATCC 9027, Staphylococcus aureus ATCC 6538, Escherichia coli ATCC 8739, Candida albicans ATCC 10231, Zygosac- charomyces rouxii NCYC 381 and Aspergillus niger ATCC 16404. The inoculated preparations were then stored at ambient temperature and samples were withdrawn at specified time intervals and the remaining micro-organisms counted.

\section{Results \\ Preservative identification}

TLC experiments were done using the standard solutions of methylparaben, propylparaben, benzoic acid and sorbic acid to rapidly check the possibility of separating and identifying all four preservatives on a single plate. Visualization was done at $254 \mathrm{~nm}$. The spots of MP, PP and SA were clearly visible on the plates. Only benzoic acid showed faint spots. Methylparaben and propylparaben were well separated from each other but there was more or less a constant $\mathrm{R}_{\mathrm{F}}$ (retardation factor) value for methylparaben and sorbic acid when different solvent systems were tried (Table 1). Changing eluent compositions did not effectively resolve all four analytes. A system that came close to a good separation was methanol : water : ammonia $(80: 10: 1, \mathrm{v} / \mathrm{v} / \mathrm{v})$ with $\mathrm{R}_{\mathrm{F}}$ values of $0.80,0.70,0.87$ for $\mathrm{MP}, \mathrm{PP}$ and SA respectively (Figure 1 ). The manufacturers and origin of the different powders are presented in Table 2. UV spectra revealed the presence of four different preservative in the dry powders; MP and PP in Artesiane ${ }^{\circledR}$, Gvither $^{\circledR}$ and Alaxin ${ }^{\circledast}$, benzoic acid in Artexin ${ }^{\circledR}$ and Santecxin $^{\circledast}$ and sorbic acid in Artenam ${ }^{\circledR}$ respectively. Cotecxin ${ }^{\circledR}$ did not exhibit any clear UV spectrum however, a personal correspondence with the manufacturers stated chlorbutanol as the preservative used. For quantification, spectrophotometry was not a good method since preservatives that exist in combination such as the parabens will absorb at the same wavelength [13]. In addition, an excipient that can interfere with the analyte cannot be separated on UV thus, HPLC-UV was used in subsequent experiments.

\section{Preservatives content and dissolution}

In the dry powders, $0.076 \% \mathrm{MP}$ and $0.020 \% \mathrm{PP}$ were found in Artesiane ${ }^{\circledast}, 0.088 \% \mathrm{MP}$ and $0.011 \% \mathrm{PP}$ in Alaxin ${ }^{\circledast}$ while $0.178 \% \mathrm{MP}$ and $0.057 \%$ PP were found in Gvither $^{\circledR}$ respectively. $0.268 \%$ sorbic acid was present in Artenam $^{\circledast}$ while Santecxin ${ }^{\circledR}$ contained $0.031 \%$ benzoic acid and Artexin ${ }^{\circledast} 0.148 \%$ benzoic acid (Table 2 ). The normal aqua concentrations of parabens used in pharmaceutical products are $0.08 \% \mathrm{MP}$ and $0.02 \% \mathrm{PP}$ (when used in combination), $0.10 \% \mathrm{BA}$ and $0.20 \%$ SA respectively [14]. However, in a powder mixture with a complex matrix these amounts may vary.

After reconstitution (addition of water) only the benzoic acid (Santecxin ${ }^{\circledast}$ and Artexin ${ }^{\circledR}$ ) and the sorbic acid (Artenam $^{\circledR}$ ) containing products completely and immediately dissolved their preservatives (Figures 2 and 3) and the levels remained unchanged during the 7 days study period. 


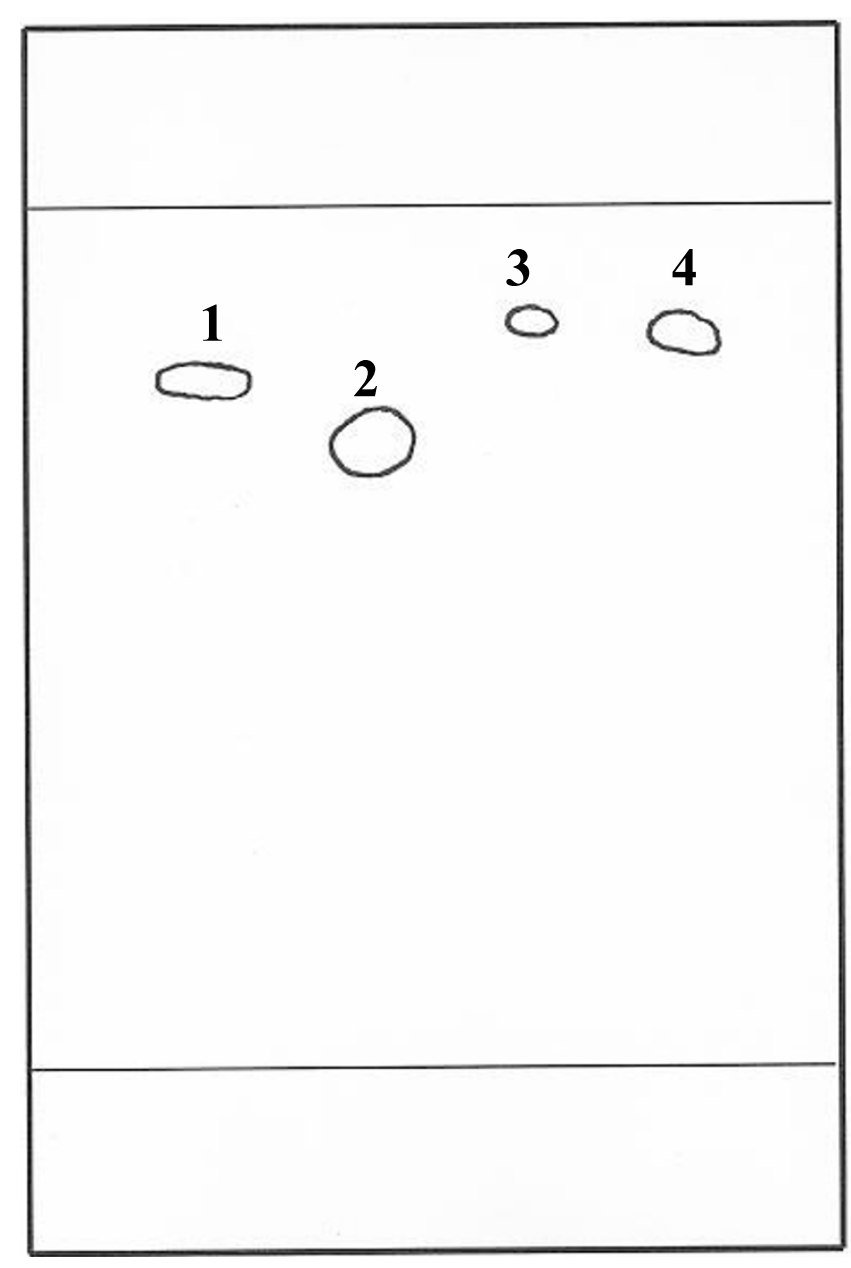

Figure I

TLC plate showing the separation of preservatives ( $\mathrm{I}=$ methylparaben, 2 = propylparaben, 3 = benzoic acid, 4 = sorbic acid) using a solvent mixture of methanol : water : ammonia $(80: 20: 1, \mathrm{v} / \mathrm{v} / \mathrm{v})$

None of the parabens immediately dissolved and the rate of dissolution differed between MP and PP in the same suspension and within different suspensions (Figures 4 and 5). Artesiane ${ }^{\varpi}$ reached the $90 \%$ dissolution rate only after 24 hrs in PP and this remained stable for up to day 7. On the other hand, the total level of MP dissolved in the same sample did not exceed $74 \%$. At $\mathrm{t}_{0}$ the amounts of preservative dissolved were $64.9 \% \mathrm{MP}$ and $85.3 \% \mathrm{PP}$ for Artesiane ${ }^{\varpi}, 28.8 \% \mathrm{MP}$ and $30.1 \% \mathrm{PP}$ for Gvither ${ }^{\circledast}$, and 78.8\% MP and 45.3\% PP for Alaxin ${ }^{\oplus}$ respectively. Gvither ${ }^{\circledast}$ possessed the most slowly dissolving parabens and only a maximum of $45.4 \% \mathrm{MP}$ and $79.2 \%$ PP were present after 7 days (Figures 4 and 5). All the drug formulations were registered at the Drug Regulatory Agency of Kenya.

\section{Efficacy of antimicrobial preservation}

A preservative efficacy test gives an indication of the antimicrobial activity of a preservative in a preparation. The preservative properties of the preparation were considered adequate if, in the conditions of the test, there was a significant fall or no increase in the number of micro-organisms at the conditions tested. In the tested wet suspensions only two samples, Artenam ${ }^{\circledast}$ and Gvither ${ }^{\circledast}$ met the specific requirements of the European Pharmacopoeia of PET in the killing of the micro-organisms. The other five products failed the test (Table 3 ). In the latter, different pathogen strains were observed with Santecxin ${ }^{\circledast}$ and Cotecxin ${ }^{\circledast}$ retaining the most species of microbes $(\geq 4$ out of 6 tested pathogens remained positive). Alaxin ${ }^{\otimes}$ and Artexin $^{\circledast}$ were positive for two microbial species while Artesiane $^{\circledast}$ was positive for one. In all samples, the fungus Aspergillus niger was the most positively tested microbe.

\section{pH of reconstituted suspensions}

Since a suitable $\mathrm{pH}$ is inevitable for the proper functioning of the preservatives, the $\mathrm{pH}$ of each reconstituted suspension was measured. The $\mathrm{pH}$ ranged from 4.50 to 5.90 in all wet suspensions (Table 3). The $\mathrm{pH}$ of two suspensions (Santecxin ${ }^{\circledast} \mathrm{pH} 5.55$ and Artexin ${ }^{\circledast} \mathrm{pH}$ 5.90) exceeded by far the $\mathrm{pK}_{\mathrm{a}}$ of their preservative, benzoicacid $\left(\mathrm{pK}_{\mathrm{a}} 4.20\right)$. The $\mathrm{pH}$ of Artenam ${ }^{\circledast}$ wet suspension was $4.50\left(\mathrm{pK}_{\mathrm{a}}\right.$ sorbic acid 4.76) while the $\mathrm{pH}$ of the Artesiane ${ }^{\circledast}, \operatorname{Alaxin}^{\circledast}$ and Gvither $^{\circledast}$ formulations were respectively 5.43, 4.40 and 4.30( $\mathrm{pK}_{\mathrm{a}}$ parabens 8.4).

\section{Discussion}

Artemisinin and its semi-synthetic derivatives are currently the most effective antimalarial compounds on the market. The dry suspension preparations of these drugs are of particular importance since they are specifically made for children (though the dose can also be adapted to an adult patient). This is a very vulnerable age group and more precaution is, therefore, necessary in formulating their medicines. In all such preparations a suitable preservative has to be added. In the tropics, where temperatures tend to be high in addition to high relative humidity, microbial contamination of the reconstituted suspension (and possible patient co-infection) can be common. In fact, in view of the possibility of using contaminated drinking water, most of the drug manufacturers advised that only boiled and cooled water should be used to reconstitute the suspension.

Regulatory law requires that preservatives must be listed by their common or usual names on ingredient labels of all drugs that contain them. Most manufacturers failed to indicate the type of preservative and the composition of other excipients in the formulation. This practice shades vital drug information, which is necessary for the patient, 
Table 2: Concentration of preservative(s) in dry suspensions after reconstitution

\begin{tabular}{|c|c|c|c|c|}
\hline Product/Manufacturer & Active ingredient/Dose & Preservative(s) identified & $\%$ preservative found & $\begin{array}{c}\text { Normal value in } \\
\mathrm{H}_{2} \mathrm{O}^{+}(\%)\end{array}$ \\
\hline Artenam ${ }^{\circledR *}$ Arenco, Belgium & Artemether $180 \mathrm{mg} / 60 \mathrm{ml}$ & Sorbic acid & 0.27 & 0.20 \\
\hline \multirow[t]{2}{*}{ Gvither ${ }^{\circledR}$ GVS Labs, India } & Artemether $300 \mathrm{mg} / 100 \mathrm{ml}$ & Methylparaben & 0.18 & 0.08 \\
\hline & & Propylparaben & 0.06 & 0.02 \\
\hline \multirow[t]{2}{*}{ Artesiane ${ }^{\circledR}$ Dafra, Belgium } & Artemether $300 \mathrm{mg} / 100 \mathrm{ml}$ & Methylparaben & 0.08 & 0.08 \\
\hline & & Propylparaben & 0.02 & 0.02 \\
\hline \multirow[t]{2}{*}{ Alaxin $^{\circledR}$ GVS Labs, India } & Dihydroartemisinin $160 \mathrm{mg} / 80 \mathrm{ml}$ & Methylparaben & 0.09 & 0.08 \\
\hline & & Propylparaben & 0.01 & 0.02 \\
\hline Artexin ${ }^{\circledR}$ Sphinx Pharma, Kenya & Dihydroartemisinin $160 \mathrm{mg} / 80 \mathrm{ml}$ & Benzoic acid & 0.15 & 0.10 \\
\hline Santecxin ${ }^{\circledR}$ Shsj, China & Dihydroartemisinin $160 \mathrm{mg} / 80 \mathrm{ml}$ & Benzoic acid & 0.03 & 0.10 \\
\hline Cotecxin $^{\circledR}$, Jiaxing Nanhu Pharma, China & Dihydroartemisinin $160 \mathrm{mg} / 80 \mathrm{ml}$ & Chlorbutanol? & Not tested & 0.50 \\
\hline
\end{tabular}

* Semi-industrial batch, + Source: Martindale (The Complete Drug Reference) 1999.

medical practitioners, researchers and the regulatory authorities.

It was not possible to use TLC alone to identify the preservatives present in the preparations due to the difficulty in separating methylparaben from sorbic acid as their $\mathrm{R}_{\mathrm{F}}$ values were nearly always the same (Table 1 ). With normal phase plates similar separation problems were encountered. The UV lamp used in spot visualization was set at two standard wavelengths only, $254 \mathrm{~nm}$ and $366 \mathrm{~nm}$ hence, the faint spots observed with benzoic acid would probably be due to its low absorption at $254 \mathrm{~nm}\left(\lambda_{\max }\right.$ BA $=226 \mathrm{~nm}$ ).

It is unclear what the recommended concentration of a preservative in a dry suspension is supposed to be. Nothing is mentioned in the United States Pharmacopoeia (USP) or the European Pharmacopoeia (Ph. Eur.) on the actual limits necessary hence, this leaves room for the formulators to employ different amounts of the same preservative; sometimes to detriment of the patient. This

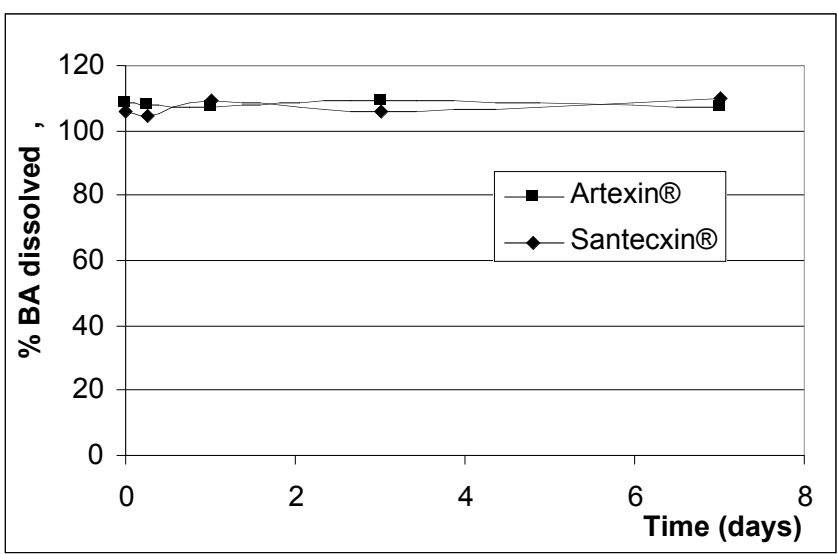

Figure 2

Dissolution profiles of benzoic acid (BA) disparity in concentration is clearly observed in all the products (Table 2 ). The total amount of a preservative present in a dry powder is required to be available in the wet suspension. None of the paraben formulations met this criterion. In some drugs, values containing as low as $30 \%$ only of preservative were released after reconstitution. This leaves the drug susceptible to contamination. The ICH recommends that content limits of the preservative of between 90-110\% at release should be acceptable. However, Ofner III et al [15] suggested that degradation of the preservative is acceptable as long as sufficient preservative is present to maintain effectiveness. To accomplish this, the use of the right type and quality of the preservative is primordial. For instance, esters of parahydroxybenzoic acids are slightly soluble in water and there is the danger that in the dry powders they may not dissolve fast enough after adding water. For such preparations, their acid salts such as sodium alkylparabens are preferred. Because the parabens took several days to reach their end concentration in the wet suspension, this may suggest that only the acid form of the preservative was used. Secondly,

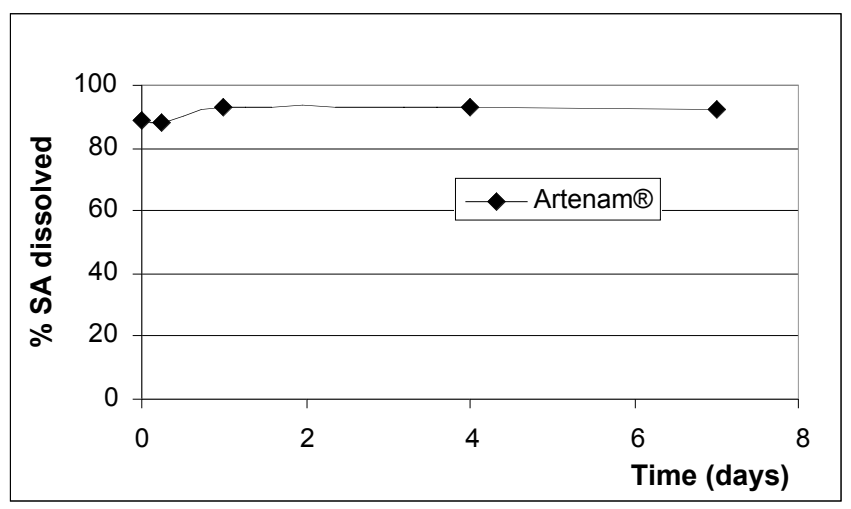

Figure 3

Dissolution profile of sorbic acid (SA) 


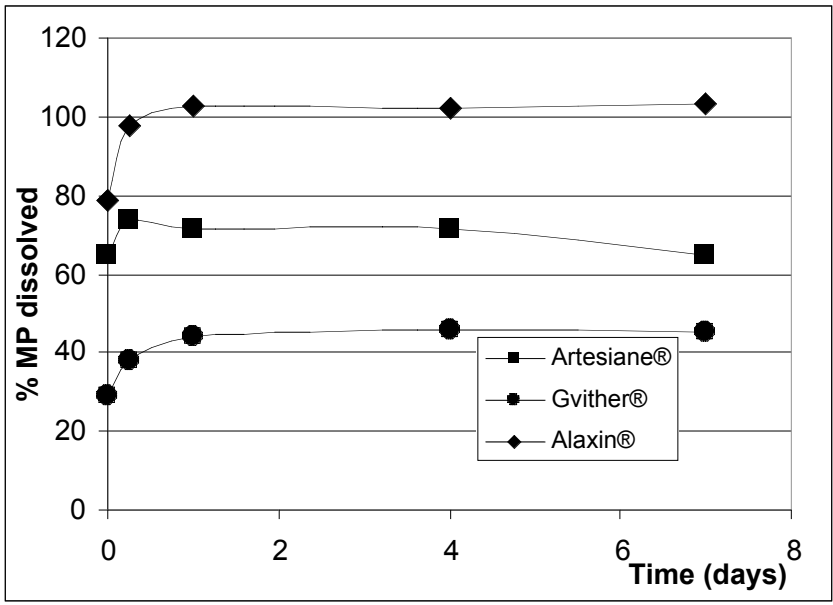

Figure 4

Dissolution profiles of methylparaben (MP)

$100 \%$ of the dissolved preservative could not be retrieved due to the possibility of preservative adsorption on the solids and/or complex formation on the macromolecules in the suspension such as suspending agents [16]. Studies have shown that parabens adsorb to the surface of the container-closure system especially plastic containers. The latter are commonly employed in paediatric formulations [17]. All products used this packaging except the Artexin ${ }^{\circledast}$ preparation which employed a brown bottle packaging. Due to the possibility of the interactions mentioned above, only the free fraction of the preservative can be active. Thus, the formulator has to be able to strike a balance between a level high enough to pass the preservative efficacy test and low enough to prevent adverse reactions.

The efficacy of a preservative depends not only on its concentration but also on the $\mathrm{pH}$ of the suspension. For preservatives that are carboxylic acids, only the un-ionized species is microbicidal. The $\mathrm{pK}_{\mathrm{a}}$ of such preservatives therefore determines the $\mathrm{pH}$ range in which the preservative is effective. The antimicrobial activity of the parabens, benzoic acid, sorbic acid and others certainly decreases as

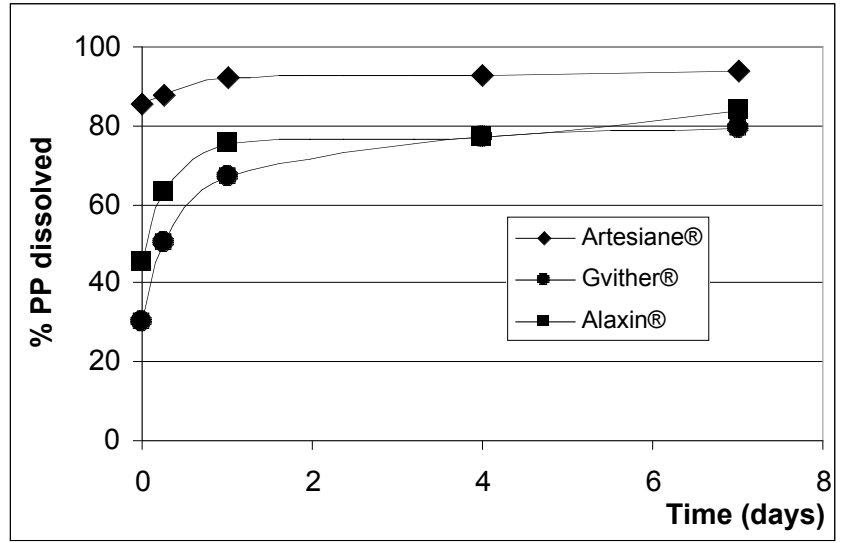

Figure 5

Dissolution profiles of propylparaben (PP)

$\mathrm{pH}$ increases past their respective $\mathrm{pK}_{\mathrm{a}}$ [5]. It is, therefore, possible that though Artexin ${ }^{\oplus}$ contained an high amount of benzoic acid $(0.148 \%)$, its antimicrobial efficacy was not adequate since the $\mathrm{pH}$ of the reconstituted suspension of 5.90 exceeded the $\mathrm{pK}_{\mathrm{a}}$ of $\mathrm{BA}$. This high $\mathrm{pH}$ dissociates the acid into the salt form leaving only a small undissociated fraction. On the other hand, Santecxin ${ }^{\circledast}$ contained a very low amount of benzoic acid (only $0.031 \%$ ) which probably was insufficient to impart the preservative's activity. The $\mathrm{pH}$ of all paraben formulations (Artesiane ${ }^{\circledast}$, Gvither $^{\oplus}$ and Alaxin $\left.{ }^{\circledast}\right)$ was lower than their $\mathrm{pK}_{\mathrm{a}}$; hence inadequate antimicrobial efficiency could not be due to chemical dissociation. Though the Gvither ${ }^{\circledast}$ sample contained the least dissolved parabens, its preservative efficacy test passed the requirements. This is probably due to the very high amounts of these substances present in the original formulation $(0.178 \% \mathrm{MP}$ and $0.057 \%$ PP respectively).

Though there are not many antimalarial dry powders on the market, a more prospective and large scale study involving samples collected in different endemic regions

Table 3: Efficacy of antimicrobial preservation of the artemisinin-derivative reconstituted suspensions

\begin{tabular}{|c|c|c|c|c|c|c|c|c|c|}
\hline & $\mathrm{pH}$ wet suspension & Preservative & P. aeruginosa & S. aureus & E. coli & C. albicans & Z. rouxii & A. niger & Ph. Eur. requirements \\
\hline Artenam $^{\circledR}$ & 4.50 & Sorbic acid & - & - & - & - & - & - & Conforms \\
\hline Gvither $^{\circledR}$ & 4.30 & MP/PP & - & - & - & - & - & - & Conforms \\
\hline Artesiane ${ }^{\circledR}$ & 5.43 & MP/PP & - & - & - & - & - & + & Does not conform \\
\hline Alaxin $^{\circledR}$ & 4.40 & MP/PP & - & + & - & - & - & + & Does not conform \\
\hline Artexin $^{\circledR}$ & 5.90 & Benzoic acid & + & - & + & - & - & - & Does not conform \\
\hline Santecxin ${ }^{\circledR}$ & 5.55 & Benzoic acid & + & - & + & + & + & + & Does not conform \\
\hline Cotecxin $^{\circledR}$ & not tested & Chlorbutanol? & - & - & + & + & + & + & Does not conform \\
\hline
\end{tabular}

$+=$ positive for the tested microorganisms, - = negative for the tested microorganisms

$\mathrm{MP}=$ methylparaben, $\mathrm{PP}=$ propylparaben 
is necessary to ascertain the impact of preservation on the products. This initial study portrays the importance of preservation in aqueous antimalarial compounds.

\section{Conclusion}

The high number of failures of the artemisinin-derivatives dry suspensions with respect to their antimicrobial preservation suggests that the surveillance of the marketed drugs may be ineffective in Kenya.

Effective preservation of paediatric formulations developed in multi-dose containers is necessary, as it contributes to the microbiological stability of the suspension as well as safeguard patient infection due to the formulation. Especially for children, paediatric medicines requiring a water phase need strict control on the content and efficacy of both the active ingredient as well as the preservative prior to registration. Above all, monitoring should continue after the drugs are on the market.

\section{Authors' contributions}

MAA participated in the study design, analysis and interpretation of data and wrote the manuscript

KDC participated in the conception, experimental analysis of the study and revision of the manuscript

JPV participated in the overall supervision of the study and critically revised the content of the paper.

\section{Acknowledgements}

The Vlaamse Interuniversitaire Raad (VLIR-UOS), Belgium is acknowledged for financial support.

\section{References}

I. Van der Meersch $\mathrm{H}$ : Review of the use of artemisinin and its derivatives in the treatment of malaria (article in French). J Pharm Belg 2005, 60:23-29.

2. Haines $A$, Smith $R$ : Working together to reduce poverty's damage. BMJ 1997, 3 I 4:529.

3. European Pharmacopoeia IV: European Directorate for the quality of medicines for the Council of Europe, Strasbourg; 2003.

4. International Committee on Harmonization: Specifications and control tests on the finished product, Directive 75/3 I 8/EEC. 1992.

5. Anger CB, Rupp D, Lo P: Preservation of dispersed systems. In Pharmaceutical Dosage forms Volume 2. 2nd edition. Edited by: Lieberman HA, Rieger MM, Banker GS. Marcel Dekker, New York; 1996:377-435.

6. Wilson LA, Kuehne JW, Hall SW, Ahearn DG: Microbial contamination in ocular cosmetics. Am J Ophthalmol 1971, 7 I: |298- I 302.

7. The Japanese standards of cosmetic ingredients-with commentary. In The Society of Japanese Pharmacopoeia 2nd edition. Yakuginippousha, Tokyo; 1984.

8. Soni MG, Burdock GA, Taylor SL, Greenberg NA: Safety assessment of propylparaben: a review of published literature. Food Chem Toxicol 2001, 39:513-532.

9. Klocker N, Kramer A, Verse T, Sikora C, Rudolph P, Daeschlein G: Antimicrobial safety of a preservative-free nasal multi-dose drug administration system. Eur J Pharmaceut Biopharmaceut 2004, 57:489-493.

10. Newton PN, Dondorp A, Green M, Mayxay M, White NJ: Counterfeit artesunate antimalarials in southeast Asia. Lancet 2003, 362:169.
II. Lon CT, Tsuyuoka R, Phanouvoug S, Nivanna N, Socheat D, Sokhan C, Blum N, Christophel EM, Smine A: Counterfeit and substandard antimalarial drugs in Cambodia. Trans $R$ Soc Trop Med Hyg 2006, 100:1019-1024.

12. Atemnkeng MA, De Cock K, Plaizier-Vercammen J: Quality control of active ingredients in artemisinin-derivative antimalarials within Kenya and DR Congo. Trop Med Int Health 2007, I 2:68-74.

13. Koundourellis JE, Malliou ET, Broussalli A: High performance liquid chromatographic determination of ambroxol in the presence of different preservatives in pharmaceutical formulations. J Pharm Biomed Anal 2000, 23:469-475.

14. Martindale: The Complete Drug Reference. 32nd edition. Pharmaceutical Press, Massachusetts; 1999.

15. Ofner III CM, Schnaare RL, Schwartz JB: Reconstituble oral suspensions. In Pharmaceutical Dosage forms Volume 2. 2nd edition. Edited by: Lieberman HA, Rieger MM, Banker GS. Marcel Dekker, New York; 1996:243-259.

16. Martin A, Swarbrick J, Cammarata A: Physical pharmacy (Physical chemical principles in the pharmaceutical sciences). 3rd edition. Lea and Febiger Press, Philadelphia; 1983.

17. Handbook of Pharmaceutical Excipients. 5th edition. Edited by: Rowe R, Sheskey P, Weller P. Pharmaceutical Press, London; 2005.
Publish with Biomed Central and every scientist can read your work free of charge

"BioMed Central will be the most significant development for disseminating the results of biomedical research in our lifetime. "

Sir Paul Nurse, Cancer Research UK

Your research papers will be:

- available free of charge to the entire biomedical community

- peer reviewed and published immediately upon acceptance

- cited in PubMed and archived on PubMed Central

- yours - you keep the copyright

Submit your manuscript here:

http://www.biomedcentral.com/info/publishing_adv.asp
BioMedcentral 